\title{
Características produtivas e nutricionais do capim-xaraés inoculado com bactérias diazotróficas associativas
}

\author{
[Productive and nutritional characteristics of Xaraés grass inoculated with diazotrophic \\ associative bacteria] \\ C.K. Bosa ${ }^{1}$, S.L. Guimarães ${ }^{2 *}$, A.C. Polizel ${ }^{2}$, E.M. Bonfim-Silva ${ }^{2}$, E.L. Canuto ${ }^{3}$ \\ ${ }^{1}$ Aluna de pós-graduação - Universidade Federal de Mato Grosso - UFMT - Rondonópolis, MT \\ ${ }^{2}$ Universidade Federal de Mato Grosso - UFMT - Cuiabá, MT \\ ${ }^{3}$ Ciência e Tecnologia de Mato Grosso - IFMT - Cuiabá, MT
}

\begin{abstract}
RESUMO
O objetivo do trabalho foi avaliar as características produtivas e nutricionais do capim- xaraés inoculado com bactérias diazotróficas associativas, em primeiro cultivo em Latossolo Vermelho do Cerrado. $\mathrm{O}$ experimento foi realizado em casa de vegetação. $\mathrm{O}$ delineamento experimental foi inteiramente ao acaso, constituído por fatorial 6x3: três estirpes de bactérias diazotróficas associativas (MTAz8, MTH2 e Y2), uma combinação das estirpes MTAz8 e MTH2, adubação nitrogenada e testemunha absoluta, e três cortes (30, 60 e 90 dias), em cinco repetições. A inoculação foi feita por meio da inserção de uma alíquota de $5 \mathrm{~mL}$ de caldo bacteriano contendo $10^{8}$ células $\mathrm{mL}^{-1}$ no solo próximo ao sistema radicular. As variáveis avaliadas foram: massa seca da parte aérea, porcentagem de proteína bruta, acúmulo e concentração de nitrogênio na parte aérea e determinação do número de bactérias diazotróficas do solo. No tratamento adubado com nitrogênio, a produção de massa seca aumentou ao longo dos cortes. Entre as estirpes de bactérias associativas, a Y2 apresentou maior acúmulo de nitrogênio e maior população de bactérias no meio de cultura LGI. As características nutricionais do capim-xaraés decaíram à medida que foram realizados os cortes.
\end{abstract}

Palavras-chave: Brachiaria brizantha, fixação biológica de nitrogênio, Cerrado

\begin{abstract}
The aim of this study was to evaluate yield and nutritional characteristics of Xaraés grass inoculated with diazotrophic associative bacteria in the first cultivation in the Cerrado Oxisol. The experiment was conducted in the greenhouse. The experimental design was completely randomized factorial $6 \times 3$ consisting of: three strains of diazotrophic associative bacteria (MTAz8, MTH2 and Y2), a combination of strains MTAz8 and MTH2, nitrogen fertilization and absolute control, and three cuts (30, 60 and 90 days) in five replicates. The inoculation was performed by inserting an aliquot of $5 \mathrm{ml}$ of the bacterial broth containing $10^{8}$ cells $\mathrm{ml}^{-1}$ in the soil near the root zone of each plant. The variables evaluated were: dry weight of shoot, crude protein, accumulation and nitrogen concentration in the shoot and determining the number of nitrogen-fixing bacteria in the soil. The fertilized soil dry matter production increased over the cuts. Among the strains Y2 showed higher accumulation of nitrogen and largest population of bacteria in the middle of the LGI culture. The nutritional characteristics of Xaraés grass declined as the cuts were made.
\end{abstract}

Keywords: Brachiaria brizantha, biological nitrogen fixation, Cerrado

Recebido em 19 de março de 2015

Aceito em 18 de fevereiro de 2016

*Autor para correspondência (corresponding author)

E-mail: slguimaraes@ufmt.br 


\section{INTRODUÇÃO}

As pastagens são de suma importância nos sistemas pecuários brasileiros e, mesmo assim, em 197 milhões de hectares de pastagens, aproximadamente 70 milhões delas estão em processo de degradação ou degradadas (Dias Filho, 2011).

O nitrogênio é o principal nutriente para a manutenção da produtividade e a persistência das gramíneas forrageiras. Sua deficiência é apontada como a principal causa de redução na produtividade e degradação das áreas cultivadas, pois o crescimento e o desenvolvimento da planta tornam-se lentos, a produção de perfilhos é negativamente afetada e o teor de proteína torna-se deficiente para o atendimento das exigências do animal (Alexandrino et al., 2010; Brambilla et al., 2012).

Uma das formas de tentar minimizar os impactos oriundos das aplicações, muitas vezes desordenadas, dos adubos nitrogenados seria a disponibilização do nitrogênio atmosférico por meio da fixação biológica de nitrogênio (FBN) realizada por bactérias diazotróficas, as quais desempenham papel importante na agricultura, pois reduzem o custo de produção das culturas (Reis Júnior et al., 2008; Guimarães et al., 2013). As bactérias diazotróficas associativas são encontradas em diferentes espécies vegetais, incluindo representantes da família Poacea (Bhattacharjee et al., 2008; Moreira et al., 2010).

As associações entre bactérias diazotróficas e as raízes de gramíneas têm sido tema de pesquisas no mundo todo, devido ao seu potencial biotecnológico, evidenciado no aumento da produtividade das culturas, à possibilidade de redução dos custos de produção ao diminuir o volume de adubos nitrogenados que são aplicados e, consequentemente, à melhor conservação dos recursos ambientais (Moreira et al., 2010).

Muitos avanços foram realizados na pesquisa sobre bactérias diazotróficas associativas, todavia ainda há muito a ser feito, desde estudos sobre os microrganismos e os processos envolvidos na associação com as plantas hospedeiras até a aplicação dessa biotecnologia pelos agricultores (Sala et al., 2007).
Assim, objetivou-se avaliar as características produtivas e nutricionais do capim-xaraés inoculado com bactérias diazotróficas associativas, em primeiro cultivo em Latossolo Vermelho do Cerrado.

\section{MATERIAL E MÉTODOS}

O experimento foi conduzido em casa de vegetação da Universidade Federal de Mato Grosso, Campus Universitário de Rondonópolis, no período de junho a setembro de 2014.

O delineamento experimental foi inteiramente ao acaso, constituído por fatorial $6 \times 3$, correspondente a seis tratamentos: três estirpes de bactérias diazotróficas associativas (MTAz8, MTH2 e Y2), uma combinação das estirpes MTAz8 e MTH2, adubação nitrogenada (com nitrogênio, fósforo e potássio) e testemunha absoluta e três cortes (30, 60 e 90 dias), em cinco repetições.

O solo utilizado foi um Latossolo Vermelho distrófico (Sistema... 2013), coletado na camada de 0-0,20m, em área de primeiro cultivo. Para a composição das unidades experimentais, o solo foi peneirado em malha de $4 \mathrm{~mm}$ de abertura e acondicionado em vasos plásticos com capacidade de $7,5 \mathrm{dm}^{3}$.

Após a coleta, uma amostra de solo foi peneirada em malha de $2 \mathrm{~mm}$ para realização das análises químicas e granulométricas conforme metodologia proposta pela Sistema (2013), apresentando as seguintes características químicas e físicas: $\mathrm{pH}\left(\mathrm{CaCl}_{2}\right): 4,1 ; \mathrm{P}\left(\mathrm{mg} \mathrm{dm}^{-3}\right)$

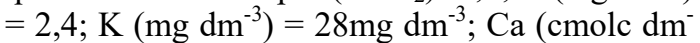
$\left.{ }^{3}\right)=0,3 ; \mathrm{Mg}\left(\mathrm{cmolc} \mathrm{dm}^{-3}\right)=0,2 ; \mathrm{H}\left(\mathrm{cmolc} \mathrm{dm}^{-3}\right)$ $=4,2 ; \mathrm{Al}\left(\mathrm{cmolc} \mathrm{dm}^{-3}\right)=1,1 ; \mathrm{SB}\left(\mathrm{cmolc} \mathrm{dm}^{-3}\right)=$ 0,6; CTC (cmolc $\left.\mathrm{dm}^{-3}\right)=5,9 ; \mathrm{V}(\%)=9,8$; matéria orgânica $\left(\mathrm{g} \mathrm{dm}^{-3}\right)=22,7$; areia $\left(\mathrm{g} \mathrm{kg}^{-1}\right)=$ 549; silte $\left(\mathrm{g} \mathrm{kg}^{-1}\right)=84$; argila $\left(\mathrm{g} \mathrm{kg}^{-1}\right)=367$.

De acordo com a análise de solo, verificou-se a necessidade de calagem, utilizando-se o método de saturação por bases para elevação a $45 \%$, com a incorporação de calcário dolomítico $(\mathrm{PRNT}=$ $80,3 \%$ ), permanecendo incubado por um período de 30 dias. Tanto no período de incubação quanto na condução do experimento, a umidade do solo foi mantida a $60 \%$ da capacidade máxima de retenção de água, por método 
gravimétrico, de acordo com Bonfim-Silva et al. (2011).

Após a calagem, foi realizada a adubação de implantação com fósforo e potássio nas recomendações de 200 e $150 \mathrm{mg} \mathrm{dm}^{-3}$, cujas fontes foram, respectivamente, superfosfato simples e cloreto de potássio. A adubação de implantação foi realizada em todas as parcelas experimentais, exceto a testemunha absoluta. A recomendação do nitrogênio para o tratamento adubação nitrogenada foi de $200 \mathrm{mg} \mathrm{dm}^{-3}$, o qual foi parcelado em duas aplicações: a primeira quando a planta tinha $10 \mathrm{~cm}$, e a segunda após sete dias da primeira, sendo utilizada a ureia como fonte (Bezerra et al., 2014).

A adubação com os micronutrientes foi realizada utilizando-se uma solução contendo ácido bórico, cloreto de cobre, cloreto de zinco e molibdato de sódio, nas doses de 1,$5 ; 2,5 ; 2,0$ e $0,25 \mathrm{mg} \mathrm{dm}^{-3}$, respectivamente (Bonfim-Silva et al., 2007).

A gramínea forrageira utilizada foi a Brachiaria brizantha cv. Xaraés, e as sementes foram semeadas, após quebra da dormência pela imersão em água, à temperatura ambiente por 24 horas, em bandejas plásticas contendo areia lavada.

Foram transplantadas 10 plantas por unidade experimental, selecionando-se as mais homogêneas. Quando as plantas atingiram $10 \mathrm{~cm}$ de altura, realizou-se o desbaste, deixando cinco plantas por vaso. Após o desbaste, todas as parcelas experimentais receberam os tratamentos (adubação nitrogenada e inoculantes).

Para produzir o inoculante, a estirpe $\mathrm{Y} 2$ foi multiplicada em meio líquido LGI (Döbereiner et al., 1995), e as estirpes MTAz8 e MTH2 foram multiplicadas em meio líquido DYGS (Döbereiner et al., 1995) sob agitação de 100rpm a $30^{\circ} \mathrm{C}$, durante 24 horas. Posteriormente ao crescimento, uma alíquota de $5 \mathrm{~mL}$ de caldo bacteriano contendo $10^{8}$ células $\mathrm{mL}^{-1}$ foi aplicada no solo próximo à área radicular de cada planta.

Foram realizados três cortes da parte aérea das plantas, com intervalo de 30 dias. Após cada corte, foi reaplicada a adubação nitrogenada $\left(100 \mathrm{mg} \mathrm{dm}^{-3}\right.$ de $\left.\mathrm{N}\right)$ apenas para o tratamento adubação nitrogenada e adubação potássica (200 $\mathrm{mg} \mathrm{dm}^{-3}$ de $\mathrm{K}_{2} \mathrm{O}$ ) para todos os tratamentos, exceto a testemunha absoluta, na forma de ureia e cloreto de potássio, respectivamente. Também foram reinoculados $5 \mathrm{~mL}$ de caldo bacteriano contendo $10^{8}$ células $\mathrm{mL}^{-1}$ nos tratamentos correspondentes à inoculação.

A coleta dos dados foi realizada em três avaliações, cada uma acompanhada de um corte. Aos 30 dias após o transplantio, foi realizado o primeiro corte das plantas a $5 \mathrm{~cm}$ da superfície do solo, coletando apenas a parte aérea e deixando $5 \mathrm{~cm}$ residuais para possibilitar a rebrota, conforme descrito por Bonfim-Silva et al. (2007).

Esse procedimento também foi mantido no segundo corte, 60 dias após o transplantio. No terceiro corte (90 dias após transplantio), as plantas foram cortadas rente ao solo.

As variáveis analisadas foram: massa seca da parte aérea, porcentagem de proteína bruta, concentração e acúmulo de nitrogênio na parte aérea e número de bactérias diazotróficas associativas no solo em relação ao meio de cultura LGI e NFb (Döbereiner et al., 1995).

A parte aérea das plantas foi acondicionada em sacos de papel, identificados e levados à estufa para secagem a $65^{\circ} \mathrm{C}$, por 72 horas, ou até massa constante. Posteriormente, esse material foi pesado em balança semianalítica para obtenção da massa seca. Após a secagem e a pesagem, as amostras foram moídas em moinho tipo Willey, com peneiras de diâmetro de $1 \mathrm{~mm}$. As lâminas foliares, colmo+bainha e raízes foram submetidos à análise de nitrogênio e proteína bruta segundo o método de Kjeldahl, descrito por Malavolta et al. (1997).

Para determinação do número de bactérias diazotróficas associativas presentes no solo, antes do preenchimento das unidades experimentais, foi retirada uma amostra representativa do solo para determinar o número de bactérias presentes no solo antes do preparo do solo e implantação dos tratamentos, e após cada corte foi retirada uma amostra homogênea de $10 \mathrm{~g}$ de solo de cada unidade experimental.

As amostras de $10 \mathrm{~g}$ de solo foram transferidas para frascos contendo $90 \mathrm{~mL}$ de solução salina, que permaneceram sob agitação constante para fragmentação dos agregados. Em seguida, $1 \mathrm{~mL}$ dessa solução foi utilizado para a realização das 
diluições seriadas de $10^{2}$ a $10^{5}$ em tubos de ensaio contendo $9 \mathrm{~mL}$ de solução salina, e, de cada diluição, $0,1 \mathrm{~mL}$ foi inoculado em $5 \mathrm{~mL}$ dos meios semissólido, LGI e NFb em três repetições.

Os frascos inoculados foram incubados por cinco dias, a $30^{\circ} \mathrm{C}$, sendo considerados positivos para a contagem aqueles que apresentaram a formação da película característica produzida por esses microrganismos.

A contagem da população de bactérias diazotróficas foi realizada por meio da técnica do número mais provável (NMP), baseada na presença da película formada no meio semissólido, utilizando-se a tabela de McCrady para três repetições por diluição (Döbereiner et al., 1995), e os valores obtidos sofreram transformação logarítmica.

Todos os dados obtidos foram submetidos à análise de variância, e, para as médias dos tratamentos, foi utilizado o teste $\mathrm{t}$ de contrastes ortogonais a $5 \%$ de probabilidade. No caso de significância da interação tratamentos $x$ cortes, realizou-se o seu desdobramento. As análises estatísticas foram realizadas pelo programa estatístico SISVAR (Ferreira, 2008). As variáveis microbiológicas foram transformadas por $(\mathrm{X}+1)^{0,5}$.

\section{RESULTADOS E DISCUSSÃO}

Com relação à massa seca da parte aérea (Tab. 1), para os contrastes $\mathrm{C} 1$ e $\mathrm{C} 2$, observou-se diferença significativa para os três cortes. No contraste C1 para o primeiro corte, observou-se que a adubação nitrogenada e a testemunha absoluta produziram, em média, $3,48 \mathrm{~g} \mathrm{vaso}^{-1}$ a menos que os tratamentos inoculados. Houve acréscimo na produção ao longo dos cortes para os contrastes $\mathrm{C} 1$ e $\mathrm{C} 2$. No que diz respeito aos contrastes entre tratamentos inoculados, não houve diferença estatística.

Os dados dos contrastes $\mathrm{C} 1$ e $\mathrm{C} 2$ demonstram que o tratamento que utilizou adubo nitrogenado apresentou maior produção do capim-xaraés ao longo dos cortes em relação aos tratamentos que não fizeram seu uso.

Martuscello et al. (2009) constataram efeito positivo do nitrogênio na produtividade de matéria seca total de plantas de Brachiaria brizantha cv. Xaraés, e segundo Rodrigues et al. (2008), o capim-xaraés é uma planta altamente responsiva à adubação nitrogenada, no que se refere à produção de massa seca.

As variáveis proteína bruta e concentração de nitrogênio apresentaram respostas semelhantes (Tab. 1). Houve efeito significativo nos contrastes $\mathrm{C} 1$ para os três cortes e no contraste C2 para o segundo e terceiro cortes.

Para a proteína bruta, observou-se no contraste C1 que a adubação nitrogenada e a testemunha absoluta apresentaram, em média, 11,78; 10,77 e $6,75 \%$ a mais que os tratamentos inoculados, respectivamente, no primeiro, segundo e terceiro cortes. Analisando o mesmo contraste para a concentração de nitrogênio, observou-se que a adubação nitrogenada e a testemunha absoluta obtiveram, em média, 18,85, 17,23 e $10,82 \mathrm{~g} \mathrm{~kg}^{-1}$ de nitrogênio a mais que os tratamentos inoculados.

Quando se analisou o contraste C2 para a proteína bruta, observou-se que a adubação nitrogenada apresentou, em média, 0,46, 7,13 e $9,10 \%$ a menos que a testemunha absoluta, respectivamente, no primeiro, segundo e terceiro cortes, e para o mesmo contraste em relação à concentração de nitrogênio, obteve-se que a adubação nitrogenada apresentou, em média, $0,74,11,41$ e $14,56 \mathrm{~g} \mathrm{~kg}^{-1}$ de nitrogênio a menos que a testemunha absoluta.

Os maiores valores encontrados na testemunha absoluta podem ter ocorrido devido ao menor porte das plantas da testemunha absoluta, aumentando a concentração de nitrogênio na parte aérea, caracterizando o chamado efeito diluição nas plantas mais desenvolvidas, no caso, a adubação nitrogenada.

A elevação nos teores de proteína bruta observada nos experimentos com gramíneas proporcionadas pela adubação nitrogenada ocorre devido ao fato de o nitrogênio participar ativamente na síntese de compostos orgânicos que formam a estrutura do vegetal (Prado, 2008). Para Mattos e Monteiro (2003) e Bonfim-Silva e Monteiro (2006), a disponibilidade do nitrogênio exerce grande influência na nutrição das plantas, o que reflete na produção e qualidade da forragem. 
Tabela 1. Estimativas dos contrastes ortogonais para o desdobramento de tratamentos dentro dos cortes na massa seca da parte aérea, concentração e acúmulo de nitrogênio e porcentagem de proteína bruta da parte aérea do capim-xaraés inoculado com bactérias diazotróficas associativas

\begin{tabular}{|c|c|c|c|}
\hline \multirow{3}{*}{ Contrastes $^{1}$} & \multicolumn{3}{|c|}{ Cortes } \\
\hline & 1 & 2 & 3 \\
\hline & \multicolumn{3}{|c|}{ Contraste estimativa - Massa seca da parte aérea $\left(\mathrm{g}\right.$ vaso $\left.^{-1}\right)$} \\
\hline $\mathrm{C} 1$ & $-3,48$ & 12,78 & 44,46 \\
\hline $\mathrm{C} 2$ & 22,17 & 42,83 & 90.39 \\
\hline $\mathrm{C} 3$ & 1,02 & 0,25 & 0,31 \\
\hline $\mathrm{C} 4$ & $-1,20$ & 0,38 & $-1,18$ \\
\hline \multirow[t]{2}{*}{ C6 } & -0.01 & $-0,21$ & $-0,56$ \\
\hline & \multicolumn{3}{|c|}{ Contraste estimativa - Proteína bruta $(\%)$} \\
\hline $\mathrm{C} 1$ & 11,78 & 10,77 & 6,75 \\
\hline $\mathrm{C} 2$ & $-0,46$ & $-7,13$ & $-9,10$ \\
\hline $\mathrm{C} 3$ & 0,95 & 0,07 & 0,17 \\
\hline $\mathrm{C} 4$ & 0,35 & 0,36 & 0,52 \\
\hline \multirow[t]{2}{*}{ C6 } & 1,36 & $-0,31$ & 0,35 \\
\hline & \multicolumn{3}{|c|}{ Contraste estimativa - Concentração de nitrogênio $\left(\mathrm{g} \mathrm{kg}^{-1}\right)$} \\
\hline $\mathrm{C} 1$ & 18,85 & 17,23 & 10,82 \\
\hline $\mathrm{C} 2$ & $-0,74$ & $-11,41$ & $-14,56$ \\
\hline $\mathrm{C} 3$ & 1,52 & 0,12 & 0,28 \\
\hline $\mathrm{C} 5$ & 0,57 & 0,57 & 0,83 \\
\hline \multirow[t]{2}{*}{$\mathrm{C} 6$} & 2,17 & $-0,49$ & 0,55 \\
\hline & \multicolumn{3}{|c|}{ Contraste estimativa - Acúmulo de nitrogênio (mg vaso ${ }^{-1}$ ) } \\
\hline $\mathrm{C} 1$ & 157,92 & 358,77 & 530,00 \\
\hline $\mathrm{C} 2$ & 724,22 & 756,72 & 791,37 \\
\hline $\mathrm{C} 3$ & 37,77 & 2,73 & 4,66 \\
\hline $\mathrm{C} 4$ & $-7,45$ & 8,01 & $-0,87$ \\
\hline C6 & 33,78 & $-5,92$ & 1,01 \\
\hline
\end{tabular}

${ }^{1} \mathrm{C} 1$ = adubação nitrogenada e testemunha absoluta $v s$. todos os tratamentos inoculados; $\mathrm{C} 2$ = adubação nitrogenada vs. testemunha absoluta; C3 = estirpe Y2 vs. estirpes MTAz8, MTH2 e MTAz8 + MTH2; C4 = estirpes MTAz8 + MTH2 vs. MTAz8 e MTH2; C5 = estirpe MTAz8 vs. MTH2.

Para o acúmulo de nitrogênio na parte aérea, verificou-se diferença significativa nos três cortes para os contrastes $\mathrm{C} 1$ e $\mathrm{C} 2$, e para o primeiro corte no C3 (Tab. 1). Nos contrastes C1 e $\mathrm{C} 2$, pôde-se observar que houve acréscimo no acúmulo de nitrogênio ao longo dos cortes, sobressaindo o tratamento nitrogenado.

No contraste $\mathrm{C} 1$, os tratamentos adubação nitrogenada e testemunha absoluta apresentaram, respectivamente, em média, 157,92;358,77 e $530,00 \mathrm{mg}$ vaso $^{-1}$ a mais que os tratamentos inoculados, enquanto no contraste $\mathrm{C} 2$ houve acréscimo de 724,22; 756,72 e 791,37mg vaso ${ }^{-1}$ a mais na adubação nitrogenada em relação à testemunha absoluta.

Essa maior extração de nitrogênio na adubação nitrogenada pode ser explicada pelo aumento de produção de massa seca, em que a planta exigiu uma quantidade maior de nutrientes para obter sua produção, ou seja, o aumento na disponibilidade do nitrogênio no solo estimula o crescimento da forrageira (Garcez Neto et al., 2002) e, consequentemente, aumenta os valores do nitrogênio acumulado na biomassa (Silva et al., 2009).

A baixa disponibilidade de nutrientes é situação comum e que restringe o crescimento e desenvolvimento das plantas (Silva e Delatorre, 2009), fato esse observado na testemunha.

No primeiro corte, para o contraste C3, as plantas inoculadas com a estirpe Y2 acumularam, em média, $37,77 \mathrm{mg}$ de nitrogênio vaso $^{-1}$ a mais que os demais tratamentos inoculados. Segundo Reis Júnior et al. (2000), existe um consenso de que o 
genótipo da planta é um fator-chave para obtenção dos benefícios propiciados por bactérias diazotróficas endofíticas.

Quando se analisaram os cortes dentro de cada tratamento (Tab. 2), notou-se que, na massa seca da parte aérea, houve diferença significativa no contraste $\mathrm{C} 1$ para todos os tratamentos e no $\mathrm{C} 2$ para adubação nitrogenada, estirpe MTAz8 + MTH2 e testemunha absoluta. Esses dados demonstram que a adubação nitrogenada e a testemunha absoluta aumentaram a produção ao longo do primeiro e segundo cortes, enquanto nas estirpes MTAz8 + MTH2 ocorreu o inverso.

Tabela 2. Estimativas dos contrastes ortogonais para o desdobramento de cortes dentro dos tratamentos na massa seca da parte aérea, concentração e acúmulo de nitrogênio e porcentagem de proteína bruta da parte aérea do capim-xaraés inoculado com bactérias diazotróficas associativas

\begin{tabular}{ccccccc}
\hline \multirow{2}{*}{ Contrastes $^{1}$} & $\begin{array}{c}\text { Adubação } \\
\text { nitrogenada }\end{array}$ & Y2 & MTAz8 & MTH2 & $\begin{array}{c}\text { MTAz8 }+ \\
\text { MTH2 }\end{array}$ & $\begin{array}{c}\text { Testemunha } \\
\text { absoluta }\end{array}$ \\
\cline { 2 - 6 } & \multicolumn{7}{c}{ Contraste estimativa - Massa seca da parte aérea (g vaso $\left.{ }^{-1}\right)$} \\
\hline C1 & $-48,98$ & 5,90 & 5,62 & 5,23 & 4,63 & $-4,55$ \\
C2 & $-53,72$ & 1,71 & 1,41 & 1,06 & 2,80 & $-6,16$ \\
\hline C1 & 11,65 & 5,43 & 5,30 & 3,96 & 4,54 & 4,00 \\
C2 & 5,07 & $-0,01$ & $-0,18$ & 0,48 & $-0,01$ & 3,10 \\
\hline C1 & 18,65 & 8,68 & 8,47 & 18,65 & 7,27 & 6,40 \\
C2 & 8,11 & $-0,01$ & $-0,28$ & 8,11 & $-0,02$ & 4,96 \\
\hline C1 & $-162,54$ & 174,34 & 162,05 & 125,81 & 132,91 \\
C2 & $-175,69$ & 11,42 & 6,92 & 13,87 & 19,27 & $-112,71$ \\
\hline
\end{tabular}

${ }^{1} \mathrm{C} 1$ : primeiro corte vs. segundo e terceiro cortes; $\mathrm{C} 2$ : segundo corte vs. terceiro corte.

Em relação à proteína bruta (Tab. 2), o contraste $\mathrm{C} 1$ apresentou diferença para todos os tratamentos, exceto para o tratamento inoculado com a combinação das estirpes MTAz8 + MTH2, e no contraste $\mathrm{C} 2$ apenas a adubação nitrogenada e a testemunha absoluta. Quando analisados os dois contrastes para a adubação nitrogenada e a testemunha absoluta, pôde-se observar que houve redução na porcentagem de proteína bruta.

As maiores mudanças que ocorrem na composição química das plantas forrageiras são aquelas que acompanham sua maturação. $\mathrm{O}$ declínio do valor nutritivo está relacionado com o avanço no estádio físiológico (Cano et al., 2004) e com a maturidade das plantas (Soares Filho et al., 2002). Essa afirmação confirma os dados encontrados neste trabalho, já que se verificou redução nos teores de proteína bruta ao longo dos cortes.

A concentração e o acúmulo de nitrogênio na parte aérea responderam de forma similar (Tab. 2), apresentando diferença estatística em todos os tratamentos para o contraste $\mathrm{C} 1$ e para a adubação nitrogenada e a testemunha absoluta no C2. Porém, ao se avaliar a concentração de nitrogênio, observou-se decréscimo em relação aos cortes para adubação nitrogenada e testemunha absoluta enquanto o acúmulo de nitrogênio obteve acréscimo ao longo dos cortes.

$\mathrm{O}$ efeito significativo para o contraste $\mathrm{C}$, quando comparado o primeiro corte aos demais cortes, pode estar associado à matéria orgânica no solo, pois Reis et al. (2001) relatam que a decomposição da matéria orgânica auxilia, de maneira limitada, no atendimento das exigências de nitrogênio das plantas forrageiras, o que justifica uma maior quantidade de nitrogênio extraída do solo apenas no primeiro corte. Além disso, a concentração de nitrogênio nos tratamentos inoculados pode ter sido oriunda da FBN das estirpes de bactérias diazotróficas associativas inoculadas nesses tratamentos.

Entre as populações de bactérias diazotróficas presentes no solo antes do plantio, verificou-se que a maior população foi detectada em meio $\mathrm{NFb}$ (Tab. 3). 
Tabela 3. Número de bactérias diazotróficas no solo (número de bactérias $\mathrm{g}^{-1}$ solo $^{-1}$ ) avaliado em meio de cultura LGI e NFb, antes da implantação do experimento

\begin{tabular}{cc}
\hline Meio seletivo & Número de bactérias $\mathrm{g}^{-1}$ solo \\
\hline $\mathrm{LGI}$ & 0 \\
$\mathrm{NFb}$ & 2,30 \\
\hline
\end{tabular}

Segundo Baldani et al. (1999), o meio $\mathrm{NFb}$ também permite o crescimento de outras bactérias endofíticas além das bactérias diazotróficas associativas, o que pode justificar o valor observado no presente estudo.
Após a implantação dos tratamentos, foi determinado, após cada corte, o número de bactérias diazotróficas associativas no solo em relação ao meio de cultura LGI (Tab. 4), onde se observou significância nos contrastes C1 no primeiro corte e $\mathrm{C} 2$ no segundo corte.

Tabela 4. Estimativas dos contrastes ortogonais para o desdobramento de cortes dentro dos tratamentos no número mais provável de bactérias diazotróficas associativas (número de células $\mathrm{g}^{-1} \mathrm{solo}^{-1}$ ) em meio de cultura LGI, em solo cultivado com capim- xaraés inoculado com bactérias diazotróficas associativas

\begin{tabular}{cccc}
\hline \multirow{2}{*}{ Contrastes $^{1}$} & \multicolumn{3}{c}{ Cortes } \\
\cline { 2 - 4 } & 1 & 2 & 3 \\
\hline $\mathrm{C} 1$ & $-3,80$ & $-1,37$ & $-0,11$ \\
$\mathrm{C} 2$ & 0,87 & 4,25 & $-1,07$ \\
\hline
\end{tabular}

${ }^{1} \mathrm{C} 1$ = adubação nitrogenada e testemunha absoluta vs. Y2; C2 = adubação nitrogenada vs. testemunha absoluta.

Isto demonstra que, no primeiro corte do contraste $\mathrm{C} 1$, a testemunha absoluta e a adubação nitrogenada apresentaram 3,80 células $\mathrm{g}^{-1} \operatorname{solo}^{-1} \mathrm{a}$ menos que o tratamento inoculado com a estirpe $\mathrm{Y} 2$. Para o segundo corte do contraste $\mathrm{C} 2$, houve aumento médio de 4,25 células $\mathrm{g}^{-1}$ vaso $^{-1}$ no tratamento adubado em relação à testemunha absoluta, em discordância de Kennedy et al. (2004), que verificaram queda nas populações de bactérias diazotróficas quando aumentadas as doses de adubo nitrogenado.

Quando se analisaram os cortes dentro de cada tratamento (Tab. 5), observou-se que o número de bactérias diazotróficas associativas no solo em relação ao meio de cultura LGI apresentou efeito significativo para os contrastes $\mathrm{C} 1$, nos tratamentos adubação nitrogenada e testemunha absoluta, e C2 na testemunha absoluta.

Tabela 5. Estimativas dos contrastes ortogonais para o desdobramento de tratamentos dentro dos cortes na cortes no número mais provável de bactérias diazotróficas associativas (número de células $\mathrm{g}^{-1} \mathrm{solo}^{-1}$ ) em meio de cultura LGI, em solo cultivado com capim-xaraés inoculado com bactérias diazotróficas associativas

\begin{tabular}{cccc}
\hline \multirow{2}{*}{ Contrastes $^{1}$} & \multicolumn{3}{c}{ Tratamentos } \\
\cline { 2 - 4 } & Adubação nitrogenada & Y2 & Testemunha absoluta \\
C1 & $-3,64$ & $-0,22$ & $-2,92$ \\
C2 & 1,46 & 0,06 & $-3,86$ \\
\hline
\end{tabular}

${ }^{1} \mathrm{C} 1$ : primeiro corte $v s$. segundo e terceiro cortes; C2: segundo corte vs. terceiro corte.

Esses dados demonstram que o tratamento cujas plantas receberam adubação nitrogenada apresentou no contraste $\mathrm{C} 1$ uma média de 3,64 células $\mathrm{g}^{-1}$ solo $^{-1}$ a menos que no segundo e terceiro cortes. $\mathrm{Na}$ testemunha absoluta no contraste $\mathrm{C} 1$, verificou-se um número de 2,92 células $\mathrm{g}^{-1}$ solo $^{-1}$ a menos que no segundo e terceiro cortes.
A testemunha absoluta no contraste $\mathrm{C} 2$ apresentou, em média, 3,86 células $\mathrm{g}^{-1} \operatorname{solo}^{-1} \mathrm{a}$ menos que no terceiro corte, demonstrando menor número de bactérias presente no segundo corte quando comparado ao terceiro, o que corrobora com Kennedy et al. (2004), que observaram aumentos populacionais na ausência ou baixa dose de nitrogênio. 
Para o número de bactérias diazotróficas associativas no solo em relação ao meio de cultura $\mathrm{NFb}$, não se observou efeito significativo, provavelmente pelo meio NFb também favorecer o crescimento de outros microrganismos diazotróficos (Baldani et al., 1999).

A contribuição da $\mathrm{FBN}$ associativa à nutrição vegetal não é tão significativa como as simbioses, entretanto, se for considerada a grande extensão de terras recobertas por gramíneas e cereais, esta se torna importante, em termos globais (Moreira et al., 2010).

\section{CONCLUSÕES}

A produção de massa seca do capim-xaraés adubado com nitrogênio aumentou ao longo dos cortes. Entre as bactérias estudadas, a estirpe Y2 apresentou maior acúmulo de nitrogênio. A maior população de bactérias diazotróficas foi encontrada no tratamento inoculado com a estirpe Y2, no meio de cultura LGI. As características nutricionais do capim-xaraés decaíram à medida que foram realizados cortes em área de primeiro cultivo em Latossolo Vermelho do Cerrado.

\section{REFERÊNCIAS}

ALEXANDRINO, E.; VAZ, R.G.M.V.; SANTOS, A.C. Características da Brachiaria brizantha cv. marandu durante $\mathrm{o}$ seu estabelecimento submetida a diferentes doses de nitrogênio. Biosc. J., v.26, p.886-893, 2010.

BALDANI, J.I.; AZEVEDO, M.S.; REIS, V.M. et al. Fixação biológica de nitrogênio em gramíneas: avanços e aplicações. In: SIQUEIRA, J.O.; MOREIRA, F.M.S.; LOPES, A.S. et al. (Eds.). Inter-relação fertilidade, biologia do solo e nutrição de plantas. Viçosa: SBCS, 1999. p.621-666.

BEZERRA, M.D.L.; BONFIM-SILVA, E.M.; SILVA, T.J.A. Wood ash effect on the productive characteristics of marandu grass in cerrado soils. Afr. J. Agric. Res., v.9, p.23392344, 2014.

BHATTACHARJEE, R.B; SINGH, A.; MUKHOPADHYAY, S.N. Use of nitrogenfixing bacteria as biofertiliser for non-legumes: prospects and challenges. Appl. Microbiol. Biotechnol., v.80, p.199-209, 2008.
BONFIM-SILVA, E.M.; MONTEIRO, F.A. Nitrogênio e enxofre em características produtivas do capim-braquiária proveniente de área de pastagem em degradação. Rev. Bras. Zootec., v.35, p.1289-1297, 2006.

BONFIM-SILVA, E.M.; MONTEIRO, F.A.; SILVA, T.J.A. Nitrogênio e enxofre na produção e no uso de água pelo capim-braquiária em degradação. Rev. Bras. Ciênc. Solo, v.31, p.909317, 2007.

BONFIM-SILVA, E.M.; SILVA, T.J.A.; CABRAL, C.E.A. et al. Desenvolvimento inicial de gramíneas submetidas ao estresse hídrico. Rev. Caatinga, v.24, p.180-186, 2011.

BRAMBILLA, D.M.; NABINGER, C.; KUNRATH, T.R. et al. Impact of nitrogen fertilization on the forage characteristics and beef calf performance on native pasture over seeded with ryegrass. Rev. Bras. Zootec., v.41, p.528536, 2012.

CANO, C.C.P.; CANTO, M.W.; SANTOS, G.T. et al. Valor nutritivo do capim-Tanzânia (Panicum maximum Jacq. cv. Tanzânia-1) pastejado em diferentes alturas. Rev. Bras. Zootec., v.33, supl.2, p.1959-1968, 2004.

DIAS-FILHO, M.B. Degradação de pastagens: processos, causas e estratégias de recuperação. 4.ed. Belém: Dias-Filho, 2011. 216p.

DÖBEREINER, J.; BALDANI, V.L.D.; BALDANI, J.I. Como isolar e identificar bactérias diazotróficas de plantas nãoleguminosas. Brasília: Embrapa-CNPAB, 1995. $60 \mathrm{p}$.

FERREIRA, D.F. SISVAR: um programa para análises e ensino de estatística. Rev. Symp., v.6, p.36-41, 2008.

GARCEZ NETO, A.F.; NASCIMENTO JUNIOR, D.; REGAZZI, A.J. et al. Respostas morfogênicas e estruturais de Panicum maximum cv. mombaça sob diferentes níveis de adubação nitrogenada e alturas de corte. Rev. Bras. Zootec., v.31, p.1890-1900, 2002.

GUIMARÃES, S.L.; BALDANI, V.L.D.; JACOB-NETO, J. Viabilidade do inoculante turfoso produzido com bactérias associativas e molibdênio. Rev. Ciênc. Agron., v.44, p.10-15, 2013. 
KENNEDY, I.R.; CHOUDHURY, A.T.M.A.; KECSKÉS, M.L. Non-symbiotic bacterial diazotrophs in crop-farming systems: can theis potential for plant growth promotion be better exploited? Soil Biol. Biochem., v.36, p.12291244, 2004.

MALAVOLTA, E.; VITTI, G.C.; OLIVEIRA, S.A. Avaliação do estado nutricional das plantas: princípios e aplicações. 2.ed. Piracicaba: Associação Brasileira para Pesquisa da Potassa e do Fosfato, 1997. 319p.

MARTUSCELLO, J.A.; FARIA, D.J.G.; CUNHA, D.N.F.V.; FONSECA, D.M. Adubação nitrogenada e participação de massa em plantas de Brachiaria brizantha cv. Xaraés e Panicum maximim x Panicum infestum cv. Massai. Ciênc. Agrotec., v.33, p.663-667, 2009.

MATTOS, W.T.; MONTEIRO, F.A. Produção e nutrição de capim braquiária em função de doses de nitrogênio e enxofre. Bol. Ind. Anim., v.60, p.1-10, 2003.

MOREIRA, F.M.S.; SILVA, K.; NÓBREGA, R.S.A.; CARVALHO, F. Bactérias diazotróficas associativas: diversidade, ecologia e potencial de aplicações. Comum. Sci., v.1, p.74-79, 2010.

PRADO, R.M. Manual de nutrição de plantas forrageiras. Jaboticabal: FUNEP, 2008. 500p.

REIS JUNIOR, B.F.; MENDES, I.C.; REIS, V.M.; HUNGRIA, M. Fixação biológica de nitrogênio: uma revolução na agricultura. Distrito Federal: Embrapa Cerrados, 2008. 32p.

REIS JUNIOR, F.B.; SILVA, L.G.; REIS, V.M.; DÖBEREINER, J. Ocorrência de bactérias diazotróficas em diferentes genótipos de canade-açucar. Pesqui. Agropecu. Bras., v.35, p.985994, 2000.
REIS, V.M.; REIS F.B.; QUESADA, D.M. et al. Biological nitrogen fixation associated with pasture grasses. Aust. J. Plant Physiol., v.28, p.837-844, 2001.

RODRIGUES, R.C.; MOURÃO, G.B.; BRENNECKE, K. et al. Produção de massa seca, relação folha/colmo e alguns índices de crescimento do Brachiaria brizantha cv. Xaraés cultivado com a combinação de doses de nitrogênio e potássio. Rev. Bras. Zootec., v.37, p.394-400, 2008.

SALA, V.M.R.; SILVEIRA, A.P.D.; CARDOSO, E.J.B.N. Bactérias diazotróficas associadas a plantas não-leguminosas. In: SILVEIRA, A.P.D.; FREITAS, S.S. (Eds.). Microbiota do solo e qualidade ambiental. Campinas: Instituto Agronômico, 2007. p.97115.

SILVA, A.A.; DELATORRE, C.A. Alterações na arquitetura de raiz em resposta à disponibilidade de fósforo e nitrogênio. Rev. Ciênc. Agrovet., v.8, p.152-163, 2009.

SILVA, C.C.F.; BONOMO, P.; PIRES, A.J.V. et al. Características morfogênicas e estruturais de duas espécies de braquiária adubadas com diferentes doses de nitrogênio. Rev. Bras. Zootec., v.38, p.657-661, 2009.

SISTEMA brasileiro de classificação de solos. 3.ed. Brasília: Embrapa, 2013. 353p.

SOARES FILHO, C.V.; RODRIGUES, L.R.A.; PERRI, S.H.V. Produção e valor nutritivo de dez gramíneas forrageiras na região noroeste do estado de São Paulo. Acta Sci., v.24, p.13771384, 2002. 